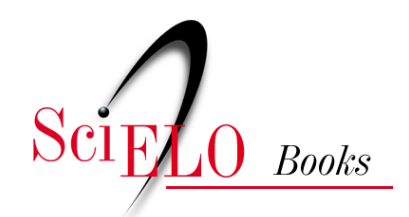

\title{
14 Tribo Vernonieae Cass.
}

\author{
Roberto Esteves \\ Benoit Loeuille \\ Jimi Naoki Nakajima \\ Danilo Marques \\ Polyana Soares \\ Vânia Esteves-Gonçalves \\ Cláudia Mendonça \\ Massimiliano Dematteis
}

\section{SciELO Books / SciELO Livros / SciELO Libros}

ESTEVES, R., LOEUILLE, B., NAKAJIMA, J.N., MARQUES, D., SOARES, P., ESTEVES-GONÇALVES, V., MENDONÇA, C., and DEMATTEIS, M. Tribo Vernonieae Cass. In: ROQUE, N. TELES, A.M., and NAKAJIMA, J.N., comp. A família Asteraceae no Brasil: classificação e diversidade [online]. Salvador: EDUFBA, 2017, pp. 101-118. ISBN: 978-85-232-1999-4.

https://doi.org/10.7476/9788523219994.0016.

All the contents of this work, except where otherwise noted, is licensed under a Creative Commons Attribution 4.0 International license.

Todo o conteúdo deste trabalho, exceto quando houver ressalva, é publicado sob a licença Creative Commons Atribição $\underline{4.0}$. 


\title{
TRIBO VERNONIEAE CASS.
}

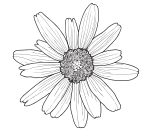 \\ Roberto Esteves \\ Benoit Loeuille \\ Jimi Naoki Nakajima \\ Danilo Marques \\ Polyana Soares \\ Vânia Esteves-Gonçalves \\ Cláudia Mendonça \\ Massimiliano Dematteis
}

A tribo Vernonieae possui uma distribuição pantropical, com grande parte das espécies concentradas no Brasil e África. Atualmente, são reconhecidas 21 subtribos, 126 gêneros e cerca de 1.300 espécies (KEELEY; ROBINSON 2009; ROBINSON, 2007).

A delimitação da tribo sofreu poucas mudanças desde o seu estabelecimento por Cassini (1816), exceto pela segregação da tribo Liabeae (ROBINSON, 1983) e Moquinieae (ROBINSON, 1994). Por outro lado, a classificação em subtribos e a circunscrição dos gêneros é bastante controversa (BREMER, 1994; ROBINSON, 1999), e boa parte dessa dificuldade taxonômica pode ser explicada pela definição do gênero Vernonia Schreb. Diversos autores aceitaram esse gênero como contendo cerca de 1.000 espécies, subdividido em inúmeras seções, subseções e séries (JONES,1979; HIND, 1993). Contudo, trabalhos mais recentes têm aceitado os gêneros reestabelecidos ou segregados a partir de Vernonia Schreb (ROBINSON, 1999, 2007; KEELEY; ROBINSON, 2009). De acordo com essa classificação, o gênero Vernonia é recircunscrito com 22 espécies no leste dos Estados Unidos, 5 espécies no México e 2 espécies ( $V$. echioides Less. e $V$. incana Less.) ocorrentes em áreas temperadas da América do Sul, incluído o Brasil (KEELEY; ROBINSON, 2009). 
A tribo Vernonieae pode ser caracterizada, em geral, por suas folhas alternas e capítulos homógamos, discoides, ramos do estilete com ápice agudo e com tricomas coletores estendendo-se abaixo da bifurcação, cipselas 3-20-costadas e pápus duplo, cerdoso ou paleáceo, raro coroniforme ou ausente (BREMER 1994; KEELEY; ROBINSON 2009). Os grãos de pólen são triaperturados (cólporos ou poros), geralmente com espinhos dispostos sobre muros em padrões regulares de lacunas (equinolofados) ou sem formar lacunas (subequinolofado) (JONES, 1979), raramente psilolofados (lacunas não ornadas por espinhos) (Apêndice A).

\section{Descrição}

Ervas perenes, raramente anuais, subarbustos a árvores ou lianas, raízes fibrosas ou com xilopódio lenhoso; ramos pubescentes ou glabros, frequentemente glanduloso-pontuados. Folhas alternas, às vezes rosulado -basais ou rosulado-suprabasais, raramente opostas ou verticiladas, sésseis ou pecioladas, inteiras ou serreado-denteadas, às vezes lobadas ou pinatissectas, pubescentes, às vezes glanduloso-pontuadas. Capitulescência corimbiforme, paniculiforme, escorpioide-cimoide, às vezes, capítulos isolados. Capítulos homógamos, discoides, flores 1-400, sésséis a pedunculados, livres ou mais raramente sincéfalos, com ou sem brácteas na base; invólucro campanulado, cilíndrico ou globoso, brácteas involucrais poucas a numerosas, multisseriadas, geralmente imbricadas, raramente uma única série; receptáculo plano ou levemente convexo, liso ou areolado, raramente alveolado, algumas vezes paleáceo ou com fimbrias. Flores bissexuais, raramente unissexuais, corola tubulosa, 5-lobada, raramente 3-4-lobada, lobos glabros ou pubescentes (Figura 7C), actinomorfa ou raramente zigomorfa, púrpura-magenta a alva ou lavanda, raro creme, avermelhada ou amarelada, frequentemente glandulosa, às vezes pubescente; anteras com apêndice do conectivo plano, alongado, ápice obtuso, raramente glanduloso, calcaradas (Figura 7G), base sagitada, obtusa ou aguda, às vezes curtamente caudada; ramos do estilete semicilíndricos, ápice agudo, raro obtuso, às vezes encurvados, com pilosidade estendendo abaixo do ponto de bifurcação, raro glabros, superfície interna com papilas estigmáticas, base do estilete frequentemente com nódulo basal. Cipselas oblongas a 
obovoide-obcônicas, cilíndricas ou levemente achatadas, 3-20-costadas, setulíferas, algumas vezes glanduloso-pontuadas; pápus cerdoso, 1 a várias séries, comumente duplo (os elementos nas 2 séries são geralmente diferentes no comprimento, forma ou ambos), com a série externa mais reduzida, elementos cerdosos capilares ou barbelados, escamiformes, paleáceos (achatados ou espiralados), raro coroniforme.

No Brasil, essa tribo é a $2^{\mathrm{a}}$ mais diversa em número de gêneros e espécies (51 gêneros e 459 espécies). Muitos gêneros e espécies são endêmicos (24 gêneros e 347 espécies), com ocorrência em todos os domínios fitogeográficos brasileiros. (BFG, 2015) Representantes de Vernonieae são encontrados nas Figuras 10, 11 e 12.

\section{Chave de identificação para os gêneros de Vernonieae no Brasil}

1. Cipselas comprimidas, atenuadas em direção à base; pápus com 1 par de aristas mais longas e 4 mais curtas (Figura 9C). Trichospira

1'. Cipselas cilíndricas; pápus variado ou ausente 2

2. Plantas com folhas geralmente em roseta; corola fortemente zigomorfa com uma incisão profunda em um dos lobos (Figuras 7K e 8H); pápus geralmente paleáceo e longo-aristado 3 2'. Plantas geralmente com entrenós conspícuos, exceto pela forma de vida caulirosulada (Figura 8G); corola actinomorfa ou levemente zigomorfa, sem uma incisão profunda em um dos lobos (Figura 7C); pápus variado. 5

3. Pápus com 5 ou mais páleas longo-aristadas, desiguais entre si, contorcidas ou uncinadas (Figura 8I). Pseudelephantopus 3'. Pápus com cerdas ou páleas longo-aristadas, subiguais, retas 4

4. Capítulos em glomérulos bracteados; cipselas 10-costadas; pápus unisseriado, paleáceo, 5-8 páleas longo-aristadas (Figura 7L), raramente curtas Elephantopus 4'. Capitulescência espiciforme; cipselas 5-costadas; pápus 2-3-seriado, cerdoso e paleáceo, cerdas numerosas, as mais internas paleáceas e longoaristadas Orthopappus 
5. Capítulos compostos, ou seja, agrupados em glomérulos (Figura 7F) ou espigas, livres entre si (capitulescência de $2^{\mathrm{a}}$ ou $3^{\mathrm{a}}$ ordem) ou fundidos (sincefalia) (Figuras 8F e 9E), mas não em ramos cimosos 6 5'. Capítulos simples, ou seja, solitários, ou organizados em cimeiras (paniculiformes, espiciformes, corimbiformes, escorpioides) (Figuras 7J e 9D) 22

6. Ervas ou subarbustos; capítulos com 4 flores, folhas caulinares 7

6'. Hábitos diversos; capítulos com números de flores diversos; se 4, então arvoretas ou subarbustos com folhas em roseta basal 9

7. Folhas com venação secundária paralelinérvea; capítulos circundados pelas folhas apicais dos ramos; brácteas involucrais cerca de 12; pápus unisseriado, aristado; grão de pólen equinolofado, tricolporado .... Soaresia 7'. Folhas com outros tipos de nervação; capitulescência de $2^{\mathrm{a}}$ ordem envolvida por brácteas involucrais (Figuras 1E e 8F); brácteas involucrais 4; pápus duplo ou pápus unisseriado e paleáceo; grão de pólen equinolofado, triporado ou porado. 8

8. Cipselas 5-costadas, pápus duplo, com a série externa de páleas curtas e largas, geralmente avermelhadas, e a interna de cerdas lineares, longas (Figura 7E); grão de pólen equinolofado, porado Caatinganthus 8'. Cipselas 8-costadas; pápus unisseriado de escamas laciniadas; pólen triporado Telmatophila

9. Ramos e eixo da capitulescência frequentemente com alas decorrentes; pólen não lofado. Gorceixia

9'. Ramos e eixos da capitulescência cilíndricos; pólen lofado 10

10. Capítulos axilares; invólucro com 2 brácteas lanceoladas, cimbiformes; 1 flor por capítulo; pápus coroniforme de páleas curtas, laceradas (Figura 8J) Rolandra

10'. Capítulos geralmente terminais; invólucro com mais de 2 brácteas; comumente mais de 1 flor por capítulo; pápus geralmente paleáceo ou cerdoso 11 
11. Subarbustos escaposos ou arbustos com folhas em roseta basal (caulirosuladas) (Figura 8G); capitulescência escaposa bracteada ............. 12 11'. Arbustos ou subarbustos, raramente árvores com folhas ao longo dos ramos; capitulescência em ramos terminais ou axilares.............................. 15

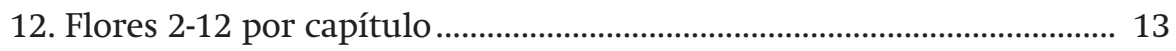

12'. Flores 20-100 por capítulo......................................................................... 14

13. Subarbustos escaposos; capítulos agrupados em glomérulos, subumbelas ou espigas, não envolvidos por brácteas involucrais de $2^{\mathrm{a}}$ ordem, longo-pedunculados (Figura 7F); pápus cerdoso, duplo, série mais externa menor e paleácea e mais interna cerdosa Chresta 13'. Plantas caulirosuladas; capítulos curto-pedunculados e dispostos em sincéfalo, envolvido por brácteas involucrais de $2^{\mathrm{a}}$ ordem; pápus 2-3-seriado, simples, cerdas subiguais

Prestelia

14. Indumento das folhas composto de tricomas em "T" inflado (Figura 8E); ápice das brácteas involucrais obtuso a agudo; 20-50 flores; pápus de cerdas Minasia 14'. Indumento das folhas composto de tricomas não ramificados; ápice das brácteas involucrais espinescente; 80-100 flores; pápus de poucas aristas decíduas Proteopsis

15. Capítulos aglomerados, dispostos em glomérulos ou espigas

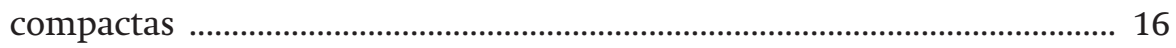

15'. Capítulos dispostos em sincéfalos (Figuras 1E, F, 8F e 9E) .................... 19

16. Arbustos ou arvoretas; capitulescência em ramos terminais................ 17

16'. Subarbustos; capitulescência em ramos axilares................................... 18

17. Margem da lâmina plana; pápus (2)3-5 séries, simples (todos os elementos cerdosos, igual ou subigual no comprimento), série interna não espiralada Eremanthus

17’. Margem da lâmina revoluta; pápus 1-2 séries, duplo, série mais interna geralmente espiralada Lychnophora 
18. Folha com face adaxial não muricada (lisa), tricomas simples; capítulos em glomérulos pedunculados; cipselas seríceas Vinicia 18'. Folha com face adaxial muricada (rugosa), tricomas armados ou simples, multicelulares (Figura 7H); capítulos em glomérulos sésseis; cipselas glabras Chronopappus

19. Folhas com bainha semiamplexicaule (Figura 8L) a amplexicaule (Figura 8M); capitulescência em ramos axilares 20 19'. Folhas sem bainha (Figura 8K); capitulescência em ramos terminais .... Eremanthus

20. Sincéfalo de $3^{\mathrm{a}}$ ordem (Figuras 1F e 9E); pápus duplo, com a série externa escamiforme ou ausente ou, ainda, coroniforme, a interna de páleas longas, achatadas, espiraladas, caducas; ápice das cerdas da série interna do pápus acuminado Lychnophora 20 '. Sincéfalo de $2^{\mathrm{a}}$ ordem (Figura 1E e $8 \mathrm{~F}$ ), pápus duplo, com a série externa de páleas curtas e a interna geralmente de cerdas longas (Figura 7D), raramente espiraladas, ápice das cerdas da série interna do pápus agudo ...

21. Hábito simpodial; indumento composto de tricomas com 3-5 braços; sincéfalo longo pedunculado, geralmente pendente na maturidade

Paralychnophora

21'. Hábito monopodial; indumento composto de tricomas em "T"; sincéfalo séssil (Figura 7B)

Maschalostachys

22. Brácteas involucrais externas foliáceas; corola com tricomas glandulares longo estipitados Centratherum 22'. Brácteas involucrais externas nunca foliáceas; corola sem tricomas glandulares, longo estipitados 23

23. Brácteas subinvolucrais conspícuas; receptáculo paleáceo ou fimbriado (Figura 7M) 24 23'. Brácteas subinvolucrais inconspícuas ou ausentes; receptáculo sem páleas e raramente com fímbrias 26 
24. Folhas sem bainha; capítulos solitários; bráctea subinvolucral trinérvia Hololepis

24'. Folhas com bainha semi a amplexicaule (Figuras 8L-M); capítulos aglomerados ou paniculiformes; brácteas subinvolucral peninérvia ....... 25

25. Folhas sésseis, superfície adaxial da lâmina bulada; cipselas com fitomelanina, glabras. Heterocoma 25'. Folhas pecioladas, superfície adaxial da lâmina lisa; cipselas sem fitomelanina, pubescentes Anteremanthus

26. Ramos com tricomas estrelados ou com 3-5 braços, inflados (Figura 7H) ou não, raramente simples 27

26'. Ramos com tricomas simples ou em "T" (Figura 8E) 32

27. Indumento com tricomas longos, escuros, multicelulares, intercalados com tricomas estrelados; brácteas involucrais internas persistentes; receptáculo fimbriado. Blanchetia 27'. Indumento variado sem os tricomas longos, escuros, multicelulares; brácteas involucrais internas decíduas; receptáculo não fimbriado 28

28. Folhas com bainha em almofada (Figura 8K); capítulos solitários ou poucos em aglomerados terminais. Piptolepis 28'. Folhas sem bainha; capitulescência terminal paniculiforme ou aglomerados axilares.

29. Capitulescência paniculiforme; estilete com nódulo basal; pápus persistente 30 29'. Capitulescência corimbiforme ou eixos reflexos; estilete sem nódulo basal; pápus interno decíduo 31

30. Ramos e folhas com tricomas estrelados; somente as brácteas involucrais mais internas decíduas; anteras, quando caudadas, com células não esclerificadas e muitas vezes distintamente dentadas Critoniopsis 30'. Ramos e folhas com tricomas estrelados ou lepidotos; a maioria das brácteas involucrais decíduas; anteras caudadas com células esclerificadas Piptocarpha 
31. Árvores ou arvoretas; invólucro cilíndrico a campanulado; brácteas involucrais sem bordos escariosos; flores 1-5 Piptocoma 31'. Ervas aquáticas; invólucro ovoide; brácteas involucrais com bordo escarioso; flores 50

Pacourina

32. Cipselas isomórficas, todas prismáticas 33 32'. Cipselas dimórficas, as mais externas aladas e as mais internas prismáticas 52

33. Capítulos com todas as flores zigomorfas ou raramente actinomorfas apenas no centro do capítulo (Figura 8D) Mattfeldanthus

33'. Capítulos com todas as flores actinomorfas (Figura 9A) 34

34. Pápus formando um tubo crasso ou paleáceo, com aproximadamente metade do comprimento da cipsela (Figura 9B) Struchium 34'. Pápus constituído de cerdas, páleas livres ou aristas, nunca formando um tubo 35

35. Ramos, folhas, brácteas involucrais, corola e cipselas densamente rubroglanduloso-pontuadas; grão de pólen equinolofado, porado.... Acilepidopsis 35'. Ramos, folhas, brácteas involucrais, corola e cipselas sem pontuações ou com pontuações de outras cores, nunca vermelhas; grão de pólen de outras formas 36

36. Brácteas involucrais concrescidas na base; receptáculo com alvéolos profundos, que envolvem quase completamente as cipselas (Figura 7A); cipselas seríceas e glanduloso-pontuadas. Albertinia 36'. Brácteas involucrais livres; receptáculo não ou superficialmente alveolado; cipselas glabras ou não. 37

37. Lobos da corola mais curtos ou do mesmo tamanho que o limbo

Cololobus 37'. Lobos da corola nitidamente maiores que o limbo (Figura 8A) 38

38. Capitulescência densamente cimoso-escorpioide (cíncino), com o ápice geralmente curvado (Figura 7J); grão de pólen subequinolofado

Cyrtocymura

38'. Capitulescência em cimeira seriada, cimeira tirsoide, corimbiforme ou paniculiforme, grãos de pólen de outras formas. 39 
39. Capitulescência em cimeira simples ou corimbiforme, nunca fortemente seriada, ou paniculiforme; pólen equinado (raramente lofado) ................. 40 39'. Capitulescência frequentemente cimosa-seriada ou capítulos em série na base de brácteas axilares, algumas vezes individualmente pedunculados; pólen geralmente lofado........................................................................... 44

40. Capitulescência paniculiforme …………………………………………... 41

40'. Capitulescência não paniculiforme (Figura 9D) ..................................... 42

41. Arvoretas a árvores; brácteas involucrais internas decíduas; anteras com base longo-caudada Gymnanthemum 41'. Ervas anuais; brácteas involucrais internas persistentes; anteras ecaudadas. Cyanthillium

42. Ervas com base decumbente; capitulescência cimosa com os ramos mais longos que o eixo central Vernonia 42'. Plantas com base ereta; capitulescência mais complexa, ramos cimosos, tirsoides ou corimbiformes 43

43. Plantas herbáceas; limbo da corola com tricomas internos; anteras com base sagitada ou aguda; cipselas com ráfides alongadas Dasyanthina 43'. Plantas lenhosas; limbo da corola sem tricomas internos; anteras com base caudada; cipselas com ráfides subquadradas Vernonanthura

44. Pápus paleáceo, páleas planas ou pápus aristado 45

44'. Pápus cerdoso ou somente a série externa paleácea e curta 47

45. Plantas terrestres; receptáculo alveolado circundado por aristas longas e fimbriadas (Figura $8 \mathrm{~N}$ ), base das anteras calcarada (Figura 80); pápus paleáceo (Figura 8P) 46 45'. Plantas aquáticas; receptáculo não fimbriado, base das anteras não calcarada; pápus com cerca de 10 aristas rígidas, espessadas na base e progressivamente estreitadas em direção ao ápice.

Xiphochaeta

46. Ervas; lâmina foliar membranácea; capítulos com 30-50 flores; pólen porado. Stilpnopappus 46'. Subarbustos ou arbustos; lâmina foliar coriácea; capítulos com 6-12 flores; pólen tricolporado Strophopappus 
47. Brácteas involucrais equinadas; pápus alaranjado quando jovem

Echinocoryne

47’. Brácteas involucrais adpressas a esquarosas; pápus de outras cores .......

48. Capítulos estreitamente cilíndricos; flores 4-10.

Stenocephalum

48'. Capítulos campanulados ou cilíndrico-campanulados; geralmente mais de 10 flores

49. Capítulos pedunculados ou sésseis em cimeiras seriadas; pólen equinolofado, tricolporado 50

49'. Capítulos sésseis localizados no meio dos entrenós, nunca em cimeiras seriadas; pólen psilofado, porado Mesanthophora

50. Brácteas subinvolucrais menores que os capítulos ou ausentes; apêndice das anteras geralmente com glândulas (Figura 7I); cipselas com pontuações glandulares entre os tricomas; pólen com 2 lacunas polares e sem lacuna equatorial.

Chrysolaena

50’. Brácteas subinvolucrais foliáceas geralmente maiores que os capítulos; apêndice das anteras sem glândulas; cipselas sem pontuações glandulares entre os tricomas; pólen com lacuna equatorial 51

51. Capítulos geralmente menores que $1 \mathrm{~cm}$ diâm., sésseis; corola com lobos com tricomas tectores; base do estilete alargada (Figura 8B).

Lepidaploa

51'. Capítulos geralmente maiores que $1 \mathrm{~cm}$ diâm., sésseis a pedunculados; corola com lobos geralmente glandulosos; base do estilete cilíndrica (Figura $8 \mathrm{C})$ Lessingianthus

52. Capitulescência cimosa; invólucro com 6 séries de brácteas livres; capítulo com 60-70 flores; grão de pólen triporado Heterocypsela 52'. Capitulescência em glomérulos ou pequenas espigas (Figura 10A); invólucro com uma série de brácteas completamente fusionadas; capítulo com 6 flores; grão de pólen tricolporado Allocephalus 


\section{Literatura recomendada}

BARROSO, G. M. Sistemática de Angiospermas do Brasil. Viçosa: UFV, 1991. v. 3.

BRAZIL FLORA GROUP - BFG. Growing knowledge: an overview of seed plant diversity in Brazil. Rodriguésia, Rio de Janeiro, v. 66, n. 4, p. 10851113, 2015.

BREMER, K. Asteraceae: cladistics and classification. Portland: Timber Press, 1994.

CASSINI, H. Tableau exprimant les affinités des tribus naturelles de familie des Synanthérées. In: CUVIER, G. (Ed.). Dictionnaire des Sciences Naturelles, Paris: Le Normant, 1816. v. 3.

HIND, D. J. N. Notes on the Compositae of Bahia, Brazil: I. Kew Bulletin, London, v. 48, n. 2, p. 245-277, 1993.

JONES, S. B. Synopsis and pollen morphology of Vernonia (Compositae: Vernonieae) in the New World. Rhodora, Cambridge, v. 81, p. 425-447, 1979.

KEELEY, S.; ROBINSON, H. Vernonieae. In: FUNK, V. et al. (Ed.). Systematics, Evolution, and Biogeography of Compositae. Vienna: IAPT, 2009. cap. 28. p. $439-470$.

LORENCINI, T. S. et al. Estudos taxonômicos do gênero Echinocoryne H. Rob. (Asteraceae, Vernonieae) no Brasil. Iheringia: Série Botânica, Porto Alegre, v. 72, n. 1, p. 16-32, 2017.

ROBINSON, H. Generic and subtribal classification of American Vernonieae.

Washington: Smithsonian Institution Press, 1999. p. 1-116. (Smithsonian Institution Press, v. 89).

ROBINSON, H. A generic review of the tribe Liabeae (Asteraceae). Washington: Smithsonian Institution Press, 1983. p. 1-6. (Smithsonian Institution Press, v. 54). 
ROBINSON, H. Notes on the tribes Eremothamneae, Gundelieae and Moquinieae, with comparisons of their pollen. Taxon, Utrecht, v. 43, n. 1, p. 33-44, 1994.

ROBINSON, H. Vernonieae. In: KADEREIT, J. W.; JEFFREY, C. (Ed.). The Families and Genera of Vascular Plants: v. 8: Flowering Plants: Eudicots Asterales. Berlin: Springer, 2007. v. VIII, p. 149-174.

ROBINSON, H.; BOHLMANN, F.; KING, R. M. Chemosystematic notes in the Asteraceae, III: natural subdivisions of the Vernonieae. Phytologia, [Huntsville,] v. 46, p. 421-436, 1980. 

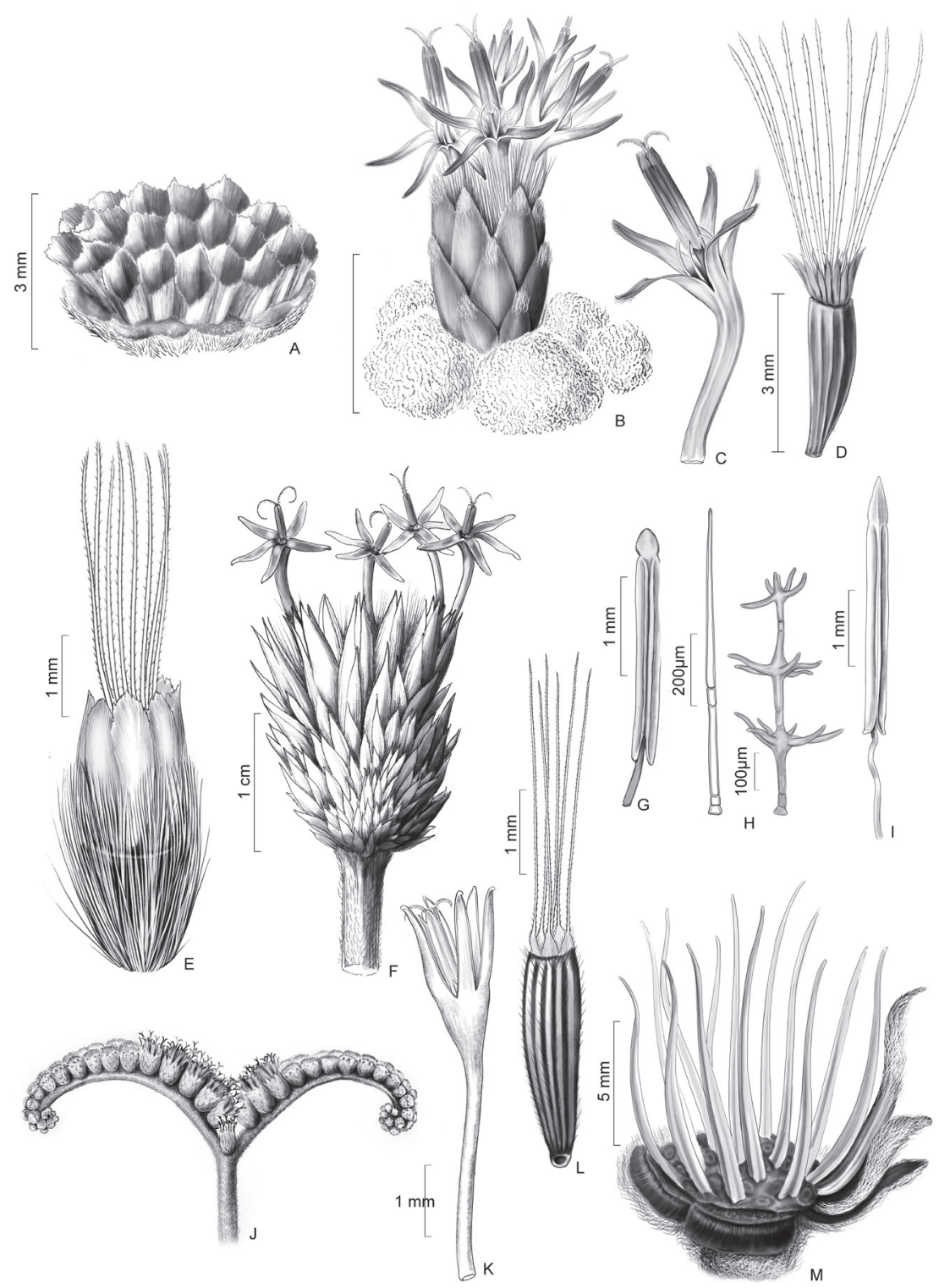

Figura 7. Vernonieae. A. Receptáculo alveolado de Albertinia brasiliensis Spreng.; B-D. Maschalostachys mellosilvae Loeuille \& Roque: B. Capítulo; C. Corola, estames e ramos do estilete; D. Cipsela e pápus duplo; E. Cipsela e pápus duplo de Caatinganthus rubropappus (Soar. Nunes) H. Rob.; F-G. Chresta harleyi H. Rob.: F. Capitulescência congesta; G. Antera calcarada (base arredondada); H. Tricomas de Chronopappus bifrons (DC. ex Pers.) DC.; I. Antera de Chrysolaena platensis (Spreng.) H. Rob.; J. Capitulescência em cimeira seriada de Cyrtocymura harleyi (H. Rob.) H. Rob.; K-L. Elephantopus mollis Kunth: K. Corola; L. Cipsela e pápus; M. Receptáculo paleáceo de Heterocoma erecta (H. Rob.) Loeuille, J.N. Nakaj. \& Semir. 


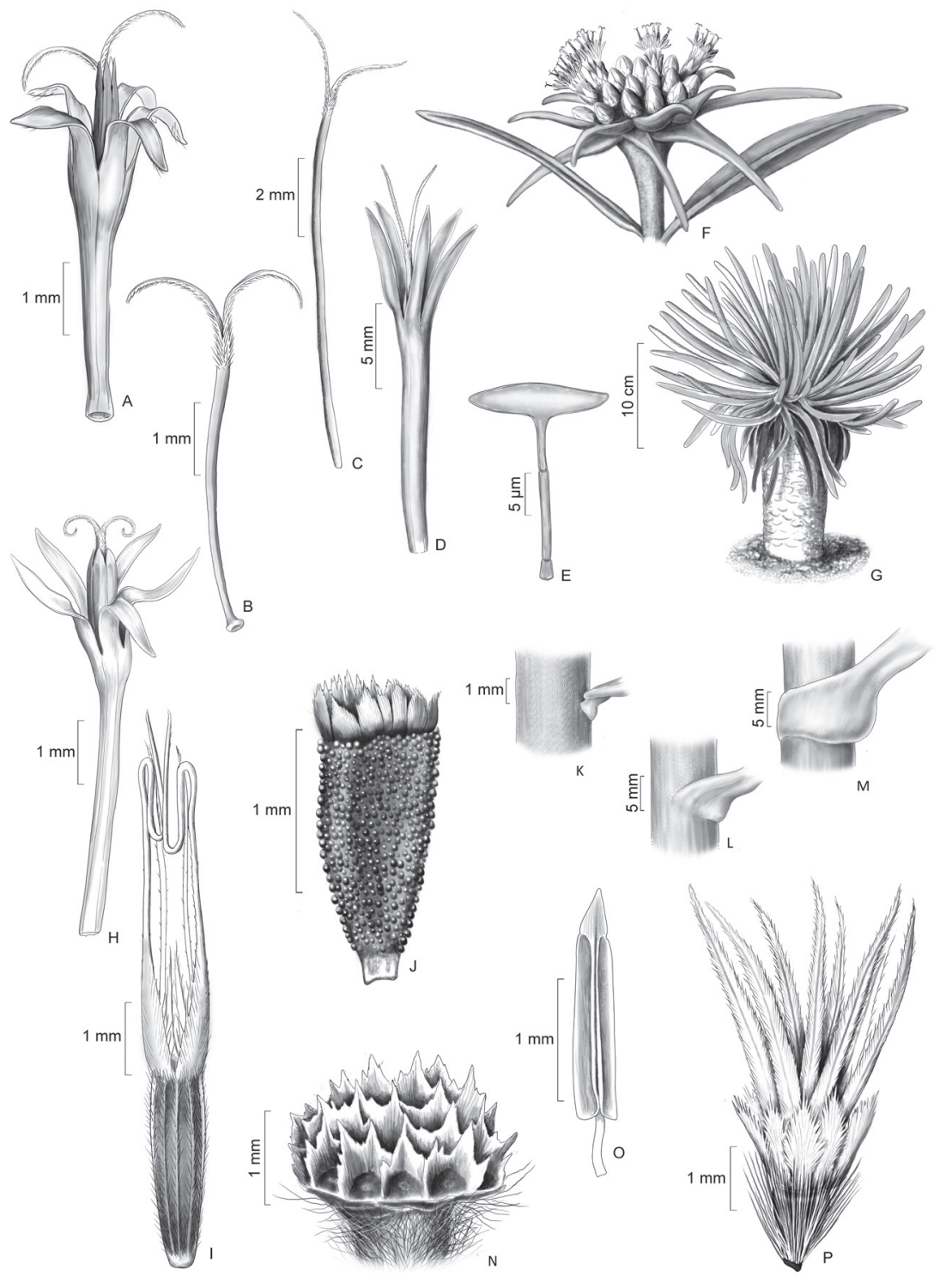

Figura 8. Vernonieae. A-B. Lepidaploa cotoneaster (Willd. ex Spreng.) H. Rob.: A. Corola com tricomas na lacínias, estames e ramos do estilete; B. Estilete com pilosidade estendendo abaixo da bifurcação, base alargada. C. Estilete (base cilíndrica) de Lessingianthus asteriflorus (Mart. ex DC.) H. Rob.; D. Corola de Mattfeldanthus mutisioides H. Rob. \& R.M. King; E. Tricoma em forma de "T" inflado de Minasia alpestris (Gardner) H. Rob.; F. Sincefalia de $2^{\mathrm{a}}$ ordem de Paralychnophora atkinsiae D.J.N. Hind; G. Forma de vida caulirosulada de Proteopsis argentea Mart. \& Zucc. ex Sch. Bip.; H-I. Pseudelephantopus spicatus (Juss. ex Aubl.) C.F. Baker: H. Corola, estames e ramos do estilete; I. Cipsela e pápus; J. Cipsela e pápus de Rolandra fruticosa (L.) Kuntze. K-M. Bainha foliar em Lychnophorineae: K. bainha em almofada (pad like); L. bainha semiamplexicaule; M. bainha amplexicaule. N-P. Stilpnopappus tomentosus Mart. ex DC.: N. Receptáculo alveolado, com ápice aristado; O. Estame; P. Cipsela e pápus duplo. 


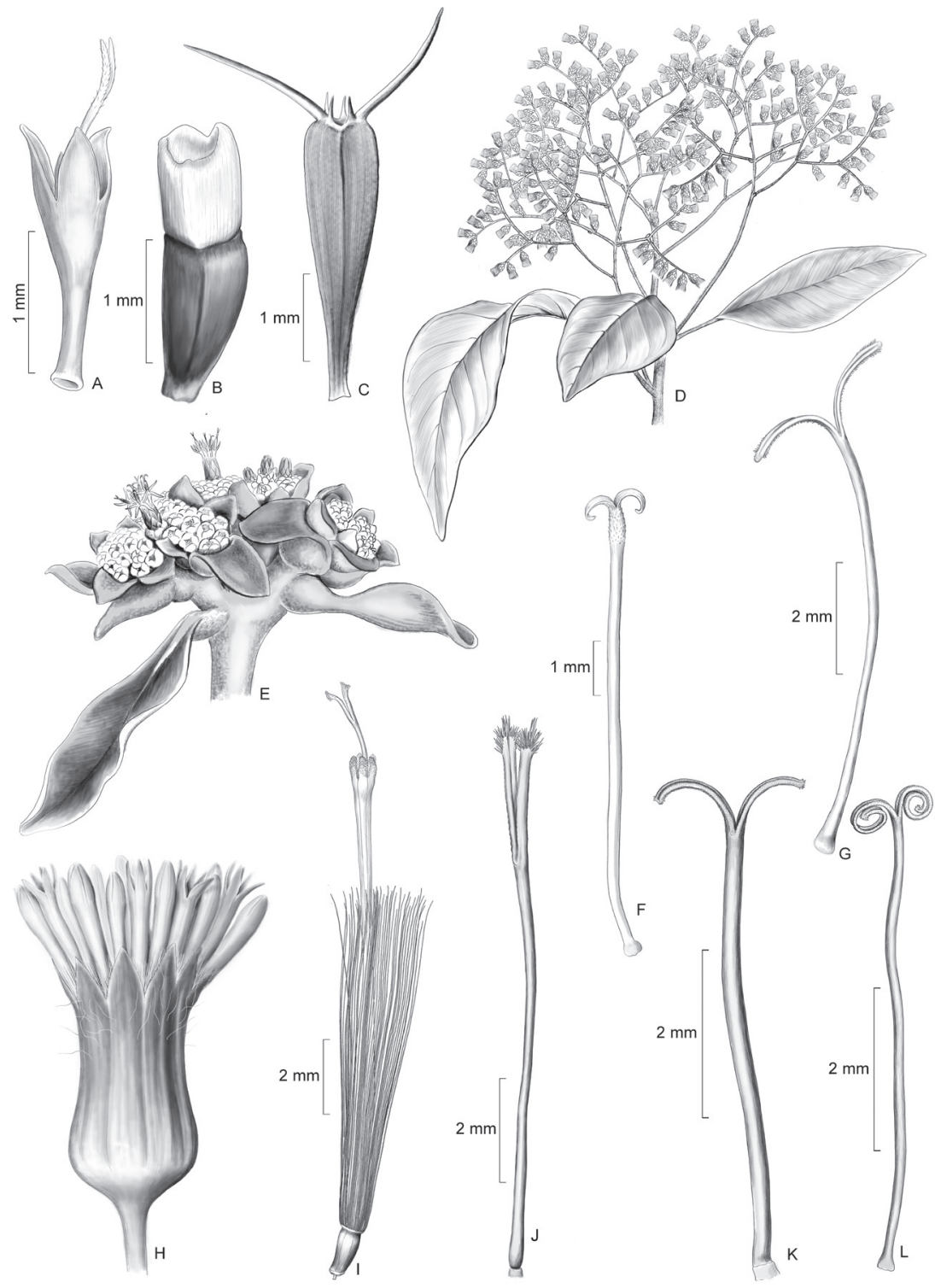

Figura 9. Vernonieae. A-B. Struchium sparganophorum (L.) Kuntze: A. Corola e ramos do estilete; B. Cipsela e pápus coroniforme; C. Cipsela e pápus de Trichospira verticillata (L.) S.F. Blake; D. Capitulescência (arranjo dos capítulos de $1^{a}$ ordem) de Vernonanthura divaricata (Spreng.) H. Rob.; E. Sincefalia com capítulos de

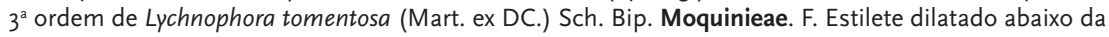
bifurcação de Moquinia racemosa (Spreng.) DC. Senecioneae. G. Estilete de Dendrophorbium pellucidinerve (Sch. Bip. ex Baker) C. Jeffrey; H. Capítulo com invólucro unisseriado de Emilia fosbergii Nicolson; I.

Flor da margem (filiforme e feminina) de Erechtites hieracifolius (L.) Raf. ex DC.; J. Estilete de Graphistylis riopretensis A.M. Teles \& B. Nord.; K. Estilete de Pentacalia desiderabilis (Vell.) Cuatrec.; L. Estilete de Senecio hemmendorffi Malme. 

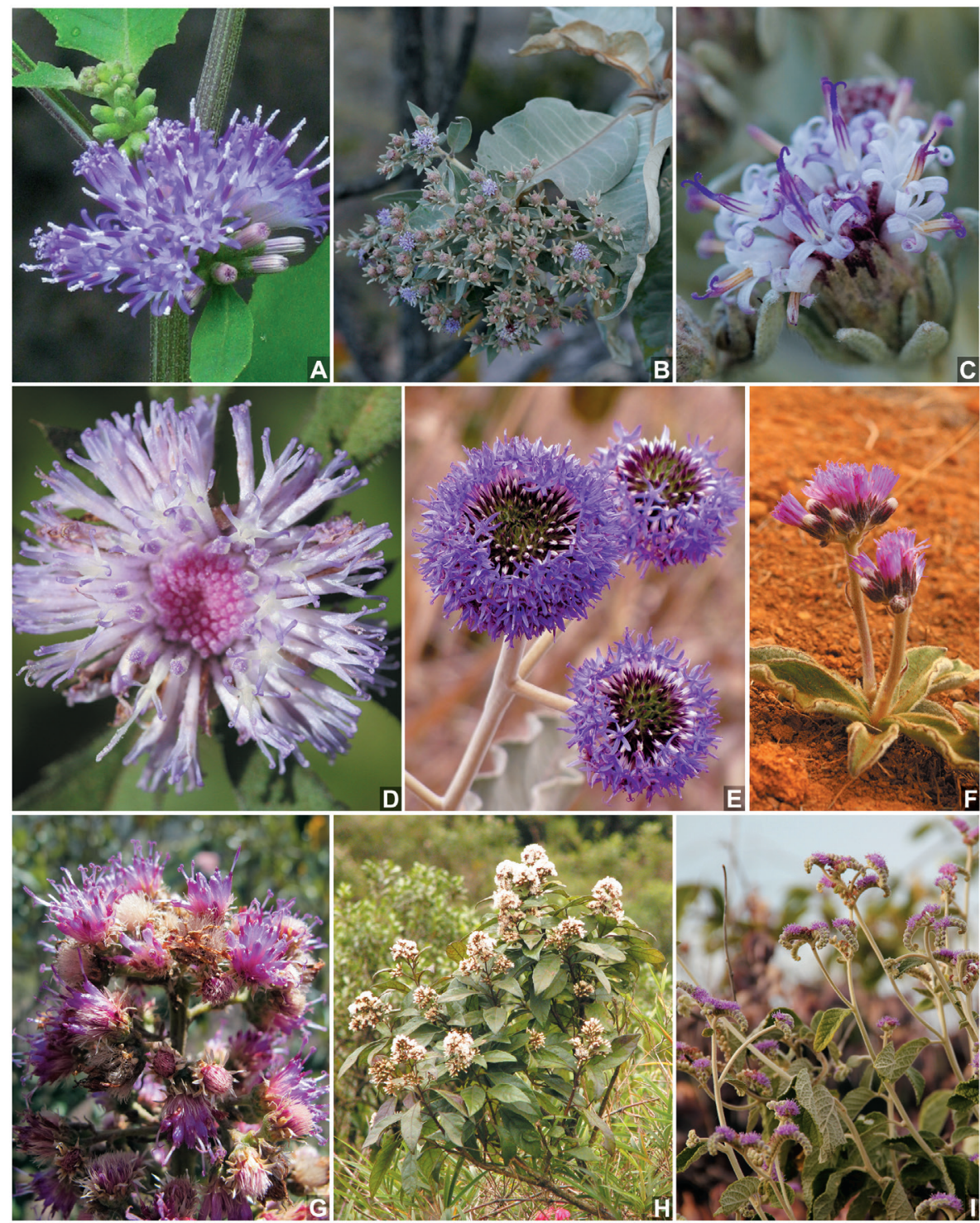

Figura 10. Vernonieae. A. Allocephalus gamolepis Bringel Jr., J.B.A., J.N. Nakaj. \& H. Rob.; B-C. Anteremanthus piranii Roque \& F.A. Santana; D. Centratherum punctatum Cass.; E. Chresta sphaerocephala DC.; F. Chrysolaena obovata (Less.) M. Dematt.; G. Cololobus rupestris (Gardner) H. Rob.; H. Critoniopsis quinqueflora (Less.) H. Rob.; I. Cyrtocymura harleyi (H. Rob.) H. Rob. 

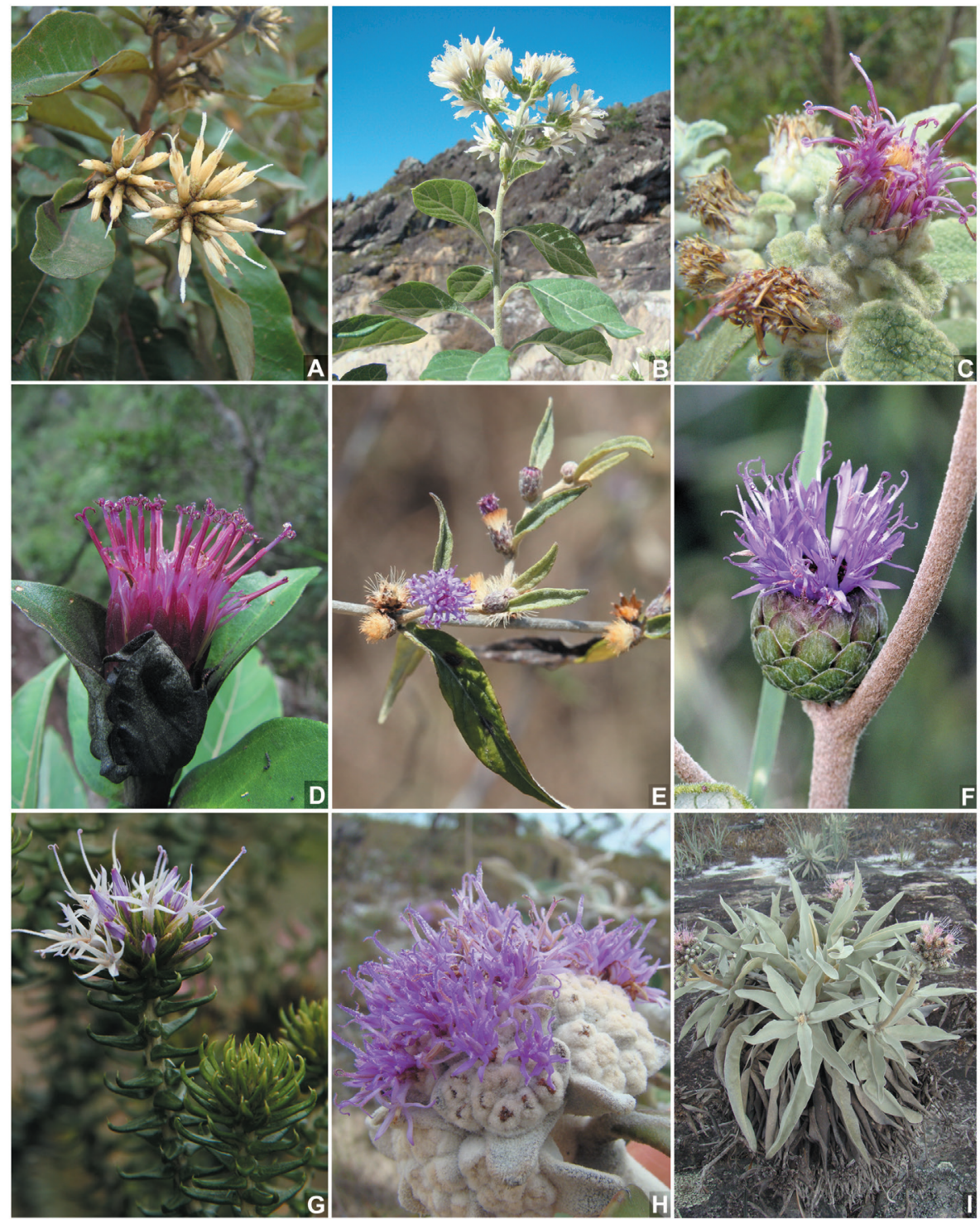

Figura 11. Vernonieae. A. Eremanthus glomerulatus Less.; B. Gymnanthemum amygdalinum (Delile) Sch. Bip. ex Walp.; C. Heterocoma erecta (H. Rob.) Loeuille, J.N. Nakaj. \& Semir; D. Hololepis pedunculata (DC. ex Pers.) DC.; E. Lepidaploa cotoneaster (Willd. ex Spreng.) H. Rob.; F. Lessingianthus monocephalus (Gardner) H. Rob.; G. Lychnophora granmogolensis (Duarte) D.J.N. Hind; H. Lychnophora tomentosa (Mart. ex DC.) Sch. Bip.; I. Minasia alpestris (Gardner) H. Rob. 


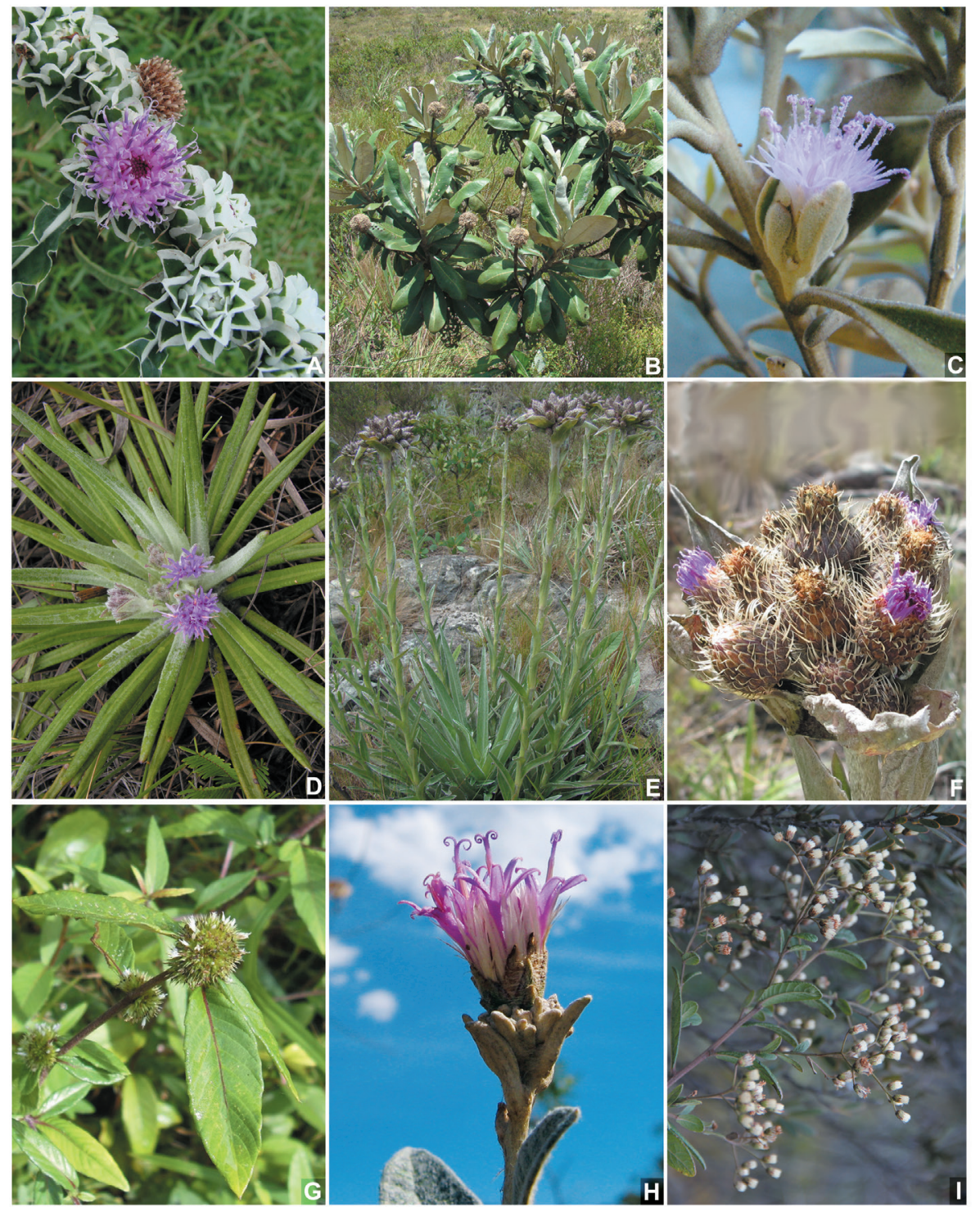

Figura 12. Vernonieae. A. Pacourina edulis Aubl.; B. Paralychnophora harleyi (H. Rob.) D.J.N. Hind; C.

Piptolepis campestris Semir \& Loeuille; D. Prestelia eriopus Sch. Bip.; E-F. Proteopsis argentea Mart. \& Zucc. ex Sch. Bip.; G. Rolandra fruticosa (L.) Kuntze; H. Strophopappus glomeratus (Gardner) R. Esteves; I. Vernonanthura brasiliana (L.) H. Rob. 